\title{
Factors Influencing Tender Hit Rate: A Case Study Based on Medical Division of ABC Holdings (Pvt) Ltd. Sri Lanka
}

\author{
Anuruddika K. K. R. Jayathilaka, R. W. M. Isuri T. Rajapakshe \\ University of Sri Jayewardenepuna, Gangodawila, Nugegoda, Sri Lanka \\ Email: anuruddikadec26@gmail.com
}

How to cite this paper: Jayathilaka, A.K.K.R. and Rajapakshe, R.W.M.I.T. (2020) Factors Influencing Tender Hit Rate: A Case Study Based on Medical Division of ABC Holdings (Pvt) Ltd. Sri Lanka. Open Access Library Journal, 7: e7006. https://doi.org/10.4236/oalib.1107006

Received: November 16, 2020

Accepted: December 13, 2020

Published: December 16, 2020

Copyright () 2020 by author(s) and Open Access Library Inc.

This work is licensed under the Creative Commons Attribution International License (CC BY 4.0).

http://creativecommons.org/licenses/by/4.0/

\section{(c) (i) Open Access}

\begin{abstract}
Health has become vital in human lives. As a result, there is a huge demand for medical equipment. It has been applied for Sri Lankan context as well. In Sri Lankan context some orgaizations use tenders for purchase of medical equipment. This study sought to investigate the factors influencing the tender hit rate of Medical division of $\mathrm{ABC}$ holdings (Pvt) Ltd. $\mathrm{ABC}$ holdings has faced a problem that some of their product were having lower tender hit rate for some product categories. This problem causes to undermine the revenue of Medical division of $\mathrm{ABC}$ holdings (Pvt) Ltd. In order to solve the problem this study investigated the factors influencing the tender hit rate. Based on the research problem two research questions were identified as what is the current level of tender hit rate? and what are the factors influencing the tender hit rate? The study aimed at achieving the following specific objectives: to examine the current level of tender hit rate and to identify the factors influencing the tender hit rate. The researcher adopted descriptive survey research design using qualitative research paradigm. Primary and secondary data collection methods used to collect data. The primary data collection instrument was a semi structured interview. The collected data were analyzed using thematic analysis. End of the study researcher is able to achieve the research objective by identifying the factors influencing the tender hit rate of Medical division of ABC holdings (Pvt) Ltd. Price should be the most influencing factor for tender hit rate in the general context of the tenders. Though, of the study researcher was able to identify the most influencing factor as Brand loyalty since this study was related to medical equipment industry.
\end{abstract}




\section{Subject Areas}

Operations Management

\section{Keywords}

Tender Hit Rate, Medical Division, Case Study

\section{Introduction}

\subsection{Background of the Study}

Health has become vital in the human life cycle. So that there is a huge and rapidly growing demand for health industry. As a result of that, medical equipment industry is expanding. According to Muhamed (n.d.) [1], medical equipment is any device that is used in the rendering of patient care. As per Department of Commerce, USA, (2016) [2], they have stated that over the past decade, the value of imported medical devices has steadily increased. The size of medical devices market 2020 reached nearly $\$ 456.9$ billion in 2019 , having increased at a compound annual growth rate (CAGR) of 4.4\% since 2015 (The Business Research Company, 2020) [3]. The market is expected to decline from $\$ 456.9$ billion in 2019 to $\$ 442.5$ billion in 2020 at a rate of $-3.2 \%$ (The Business Research Company, 2020) [3]. Based on those facts, medical equipment industry in the global context has high competition and growing trend. In the Sri Lankan context, there is a competitive industry for medical equipment. In the Sri Lankan context, some of the organizations use tendering processes to purchase medical equipment. Purchasing companies are called as "Tenderers" and selling companies can have called as "Bidders". Firms generate revenue by selling their products while contractors generate revenue by winning projects (Aje, Oladinrin, \& Nwaole, 2016) [4]. In order to increase the sales bidders, there is need to increase the winning rate of the tenders. In general, this rate is expressed as hit rate. Business dictionary stated that tender hit rate is the number of sales realized as a percentage of the number of sales calls (visits) or inquiries received. We can identify many factors affecting the tender hit rate. Many researches focused on the factors influencing tender hit rate relating to the construction industry. However, price and quality are common for all the industry.

\subsection{The Research Problem/Research Question}

Research problem of the study is "What are the factors influencing the tender hit rate of Medical division of $\mathrm{ABC}$ holdings (Pvt) Ltd.?". Based on that research problem, following research questions can be identified in terms of Medical division of ABC holdings (Pvt) Ltd.: what is the current level of tender hit rate? and what are the factors influencing the tender hit rate? Meanwhile followings are the objectives that were to be expected to achieve in this research which was based on the Medical division of $\mathrm{ABC}$ holdings (Pvt) Ltd.: to examine the current level of 
tender hit rate and to identify the factors influencing the tender hit rate.

\section{Literature Review}

Tender process is the process, where the customer states the system requirements, a number of suppliers submit their proposals and customer selects one of them (Lausen, n.d.) [5] [6]. As per Department of Commerce, USA, (2016) [2], they have stated that over the past decade the value of imported medical devices has steadily increased, gradually eroding the previous trade surplus where tender process in involved. The majority of imports are lower-tech products, such as surgical gloves and instruments. As per this statement, this decline in import of United States affected the decline of exports in Sri Lanka.

Hit rate (bid-hit rate) means a rate at which organizations successfully bid on tenders. Hit rate highly depends on the price of the tender. Price should be the lowest to win the bid compared to the other competitive bidders. The main factors affecting for Tender hit rate are Bidding price, quality, competitiveness, tender specifications, reference and availability, bribes, registration, mistakes made by employees, bidder's experience in the industry and few other (Florence and Min, 2005, cited in Aje, et al., 2016) [4] stated that quality of the product is also affected to achieve higher hit rate. Contractors who are successful would place more emphases on factors that affect schedule, cost and quality of the projects (Florence and Min, 2005 cited in Aje, et al., 2016) [4].

The bidding price depends significantly on the market or competitive environment surrounding a particular construction project (Laryea \& Hughes, 2010 cited in Aje, et al., 2016) [4]. According to Alexandersson, G., and Hultén, S. (2006) [7] increased competition leads to more aggressive bidding. Also McGuire, J. (2006) [8] stated that competition plays a key role in bidding success. Competitors, their bidding trends and also number of contractors that are bidding a project needs to be considered when bidding. According to the Baldwin et al. (as cited in McGuire, J. 2006) [8] competition is one of the factors which determines bid's chance of success.

In previous literature mentioned about the neediness of the matching tender specification to win the tenders. Product specifications should be made clear. Slanting product specifications need to be discouraged (Ngugi, J., \& Mugo, H., n.d.) [9]. Tender documents specifically mentioned about the tender specification. Tender advertising on the Galle Fishery harbor mentioned that responsive to the tender documents shall be rejected essentially, if available product does not conform to the required specifications, or contains inadmissible reservations or otherwise is not substantially responsive to the Tender Documents, it shall be rejected. According to that it is clear tender specification is main factor that needs to consider by bidder.

When selecting the best bidder sometimes tenderers consider about the user references. Ngugi, J., and Mugo, H., (n.d.) [9] stated that, successful hospital procurement is also a collaborative process, involving people with skills in purchasing, finance, management, clinical and nursing specialties, pharmacy, quali- 
ty control, and even the end user: the patient. Accordingly, when selecting the product many people involve for the analysis. So tenderers accept the product after consider the likeliness of the analyzing committee.

Otieno (2004) (cited in Ngugi, J., and Mugo, H., n.d.) [9] mentioned in his study as, the irregular procurement activities in public institutions provide the biggest loophole through which public resources are misappropriated. Here he emphasized about the bribes as main barrier to the effective tender process. Not only that, Otieno (2004) (cited in Ngugi, J., and Mugo, H., n.d.) [9] mentioned that, Lack of accountability creates opportunities for corruption. Daily news paper mentioned about the frauds taken place in Sri Lankan context. Thushara, R. (2018) [10] stated that; Presidential Commission investigating into alleged frauds taken place at Sri Lankan Airlines, Sri Lankan Catering and Mihin Lanka that the tender to supply duty free items is renewed once in every six months, but these companies were offered the contract for seven years continuously under Wickremasinghe's administration.

There are some rules and regulation that should have to follow when awarding tender in order to mitigate the risk of frauds. Internationally, all Public entities are subjected to open tendering by law so as to prevent fraud, waste, unethical practices or local protectionism (Global trade negotiation, 2006 as cited in Ayoti, B., 2012) [11]. Similarly, ethical behavior can reduce the cost of managing risks associated with fraud, theft, corruption, and other improper behavior; and enhance confidence in public administration (Wee, 2002 cited in Ngugi, J., and Mugo, H., n.d.) [9]. Accordingly, ethical behaviors of the tenderers and bidders undermine the bribery and corruptions.

Since these tenders are relating with the medical equipment it is essential having required registration with respective authorities. This is mentioned in the study of Ngugi, J., and Mugo, H., (n.d.) [9] as, Market approval (or registration) of pharmaceutical products should be granted on the basis of efficacy, safety and quality. According to that registration is a factor which ensures the quality of the product. So that tenderers really focused on this factor. There is a requirement mentioned in Galle fishery tender invitation, as copy of Business Registration or certificate of Incorporation should be attached. So that it is essential to register in required places in order to win the tender.

Error free computations are required in the tender invitation of Galle fishery habour. Tender documents with the errors will be rejected accordingly. As per GOK, (as cited in Ayoti, B., 2012) [11] records of some of the procurement transactions were found to be inaccurate or incomplete or absent, which led to suspicions of dishonest dealings at the tender boards.

Article of the Daily FT newspaper wrote as, the evaluation of technical proposal ensures the bonds are proper and ensure that the tenderer has enough experience, technical and financial capacity to carry out the project. Tenderers consider the bidders experience regarding the related industry when evaluating the tender.

Aje et al. (2016) [4] have been identified some related factors influencing the 
tender prices based on literatures in the construction industry of Nigerian context. Those are Material availability (Liu et al., 2007), Labour productivity (Elhag, et al., 2005; Shash, 1993), Level of profit (Park \& Chapin, 1992), Project financing (Han \& Diekmann, 2001), Cost of manpower (Shash, 1993), Location and control of site (Akintoye, 2000), Zonal rates (Zou, 2007), Category of contractor (Shen et al., 2004), Management ability (Hatush \& Skitmore, 1999), Contract type (Drew \& Skitmore, 1997) (Aje et al., 2016) [4].

Kissi, Adjei-Kumi, Badu, and Boateng (2017) [12] found that based on his literatures the factors that affect tender pricing can be grouped under the following constructs: contractor attributes (CON), project attributes (PRO), contract procedures and procurement methods (CONT), external factors and market conditions (EXT), client attributes (CL), consultant and design parameters (CS), sustainable and technological attributes (SS), fraudulent attributes (FRA) cultural attributes (CA) and Tender Pricing Indexes (TPI).

However, factors affecting the bidding decisions are varied from the one industry to another. As an example, factors that are affecting the hit rate of the construction industry sometimes may not match with the influencing factors of the medical equipment industry. Because they are in two different industries, competitors as well competition are different, products are different (medical equipment are consumable goods), clients and their requirements on tenders are different. However, management can increase the likelihood of winning the tender and acquiring prospective new customers by taking into consideration the influencing factors for win tenders.

Sometimes companies do not bid on some tenders. Bid or no bid decisions are taken by the respective authority of the company. The risk is always accompanied with the decision taken, as it will directly affect the profitability of the organization. According to the Invest Northern Ireland (2012) [13] it is stated that "Be patient and wait for the tender opportunity that is right for your business it is a waste of time tendering for contracts that you are not going to win. The most common reason for lack of success is poor choice of tender opportunity." Also Garrett points out that a simple, repeatable, and effective bid/no bid decision making process can be valuable to a company by reducing costs and improving revenues and profits (Garret, 2005 cited in Lemberg, 2013) [14]. So that there is a need for effective bidding in each and every industry as company resources are scarce and bidding for badly chosen requests may result in great loss of time and other assets.

Also, there may be issues in tendering process relating to PPP (Private Public Partnership) the first one is about the procedure to follow in the tender: different phases can form the PPP tendering process, but some of them can be missing in some cases. Secondly, there are different awarding methods used in real projects and some other ones are proposed in the literature. Lastly, due to the complexity of such projects, most of the cited awarding methods are assessing different factors: consequently, it is important to provide a collection of the used evaluation 
criteria. (Carbonara, et al., 2012) [15]

\section{Methodology}

The study adopted qualitative method to achieve the aim of the research. In ontology it is concern about how the researchers see the world. It is about a metaphysical study of the nature of being and existence. In my case as I am acting as a subjectivist, I hope to go in line with post positivism dimension. Post positivism do not emphasize the independence between the researcher and the object while accepting that their knowledge, values, theories and background can influence what is observed. Not like doing a quantitative research in qualitative aspect I cannot follow positivism which is epistemological position that advocates the application of methods of natural sciences to study of the selected phenomena. Thus, in line with my research question anti-positivism or constructivism, which is social phenomena and their meanings are continually being accomplished by social actors, should be used as I believe that reality is constructed.

Primary and secondary data sources used as the data collection method. Semi structured interviews conducted as a method of primary data collection. In semi structured interviews, the researcher will have list of themes and questions to be covered throughout the interviews, allowing for a discussion with the interviewee rather than a straightforward question and answer format. Where, researcher can ask questions predetermined questions as well as questions that arose while conducting interviews. Semi structured interviews conducted with the persons who work in the $\mathrm{ABC}$ medical as employees. A literature review was constructed to identify those factors affecting the lower tender hit rate in different industries. Secondary data collected from internal or external sources of the company. Individual employees who work in the $\mathrm{ABC}$ medical division taken as a unit of analysis of the study. Target population comprise with bidders of medical equipment industry. Through that I have selected a sample of one specific organization which is $\mathrm{ABC}$ medical division. Convenience sampling used to select the sample of the study. Accordingly, I have interviewed 8 employees and the details of the employees can be summarized as per Table 1 .

Qualitative data analysis is relatively somewhat difficult task. However, the study is based on the qualitative technique, thematic analysis used to analyze the data collected through the primary data collection techniques. Since the study is qualitative, research strategy involves case study method. Design of the research is descriptive because the study is based on the existing problem in the company.

\section{Findings and Discussion}

My first research question is, what is the current level of tender hit rate? To answer this question, I gathered data from the list of tenders they have participated during the year 2019 and the list of awarded tenders during the year. By using those secondary data, I have calculated their tender hit rate separately for each product category for the year 2019. 
According to the calculated hit rate they have the lowest hit rate for the Medical instruments and the highest hit rate for the Biotechnology. If we consider the Medical instrument tenders, they have participated for 71 tenders during the year 2019 however they awarded only 4 tenders. It is very less number compared to the participated tenders. In this category they have REISTER brand products mostly. When analyzing the awarded tenders I have recognized those are awarded due brand, model and one tender were awarded due to the lower price. Also, out of the awarded tenders 3 tenders were from Sri Jayewardenepura hospital. Biotechnology has 39\% hit rate (Table 2). ABC medical division was participated for 36 tenders during the previous year, from that they have awarded 14 tenders. Price, model and good brand are the main reasons for those awarded tenders. However, they have awarded one tender due to the model though they were 4th lowest bid compared to the others. In this category their brand is BIORAD which is the world number one brand. This creates a huge advantage for the company since tender evaluators consider mostly about the brand name. Out of the awarded list 2 awarded tenders are from the University of Sri Jayewardenepura. In Cardiology range they participated for 39 tenders and awarded

Table 1. Basic Information of the interviewees (Source: Author compiled data).

\begin{tabular}{ccccc}
\hline Number & Gender & Age & Designation & $\begin{array}{c}\text { Working experience at ABC } \\
\text { holdings medical division }\end{array}$ \\
\hline 1 & Female & $25-30$ years & Junior executive & 2 years \\
2 & Male & $55-60$ years & Senior manager & 2 years \\
3 & Male & $40-45$ years & Sales manager & 3 years \\
4 & Male & $35-40$ years & Product manager & 6 months \\
5 & Male & $35-40$ years & Manager-Administration & 8 years \\
6 & Male & $35-40$ years & Sales manager & 7 years \\
7 & Male & $35-40$ years & Product manager & 6 years \\
8 & Male & $50-55$ years & Sales manager & 7 years \\
\hline
\end{tabular}

Table 2. Calculated Tender Hit Rate using secondary data collected (Source: Author compilation).

\begin{tabular}{cc}
\hline Product category & Hit rate \\
\hline Biotechnology & $39 \%$ \\
Cardiology & $26 \%$ \\
Laboratory instruments & $21 \%$ \\
Medical instruments & $6 \%$ \\
Radiology & $11 \%$ \\
\hline
\end{tabular}


only 10 tenders which have $26 \%$ hit rate. This range possesses the second highest hit rate. LABTEC and ZONCARE are the brands that won the tenders in this range, also there are some other brands, but they did not award any offer. Brand and lower prices are the reasons for won the tenders. Sri Lanka Air force is the responsive tenderer for half of the awarded tenders. $\mathrm{ABC}$ medical division able to award all the tenders called by the Sri Lanka Air force and brand name is the reason for award those tenders regularly. Laboratory instrument recorded the highest participation for tenders when compared to the other categories. Throughout the year $\mathrm{ABC}$ medical division was participated for 213 tenders and awarded 45 tenders. This range has only $21 \%$ hit rate, but when comparing number wise this has the highest number participated tenders and the highest number of awarded tenders. This category has different types of brands but most of them are related to brand name of BIOBASE. Price, model and the brand are the reason for award the tenders. Radiology category has $11 \%$ hit rate from the 18 participations. From that they awarded only 2 tenders due to the price and brand. ZONCARE and DRTECH are the brands in the Radiology range. Accordingly, Medical division of $\mathrm{ABC}$ holdings has different levels of hit rate for the different product categories. If I take the average hit rate, they have nearly $21 \%$ hit rate.

As per my second research question I hope to identify the factors influencing tender hit rate of Medial division of ABC holdings (Pvt) Ltd. Through the secondary data analysis can be identified factors influencing tender hit rate. Accordingly, I have identified some factors from analysing the awarded tender list for the year 2018. Those factors are Bidding price, Brand of the product and Model of the product. Based on the identified themes I have explored some major factors influencing the tender hit rate. From here onwards my discussion is about the factors influencing the tender hit rate.

All of the interview participants have been identified the Bidding price as a factor and I have named it as Affordability. Lower bidding price helps to win the tenders most of the time. Affordability is the most affecting factor among the all. According to the collected data bidding price should be low enough to win the tender. Bidding price is main considering factor in the government sector tenders since the budget is limited. Based on the number of interviewees who named bidding price as a factor can conclude that, affordability as the most influencing factor. However according to my view point affordability is not the mostly influencing factor in the Medical equipment industry because the other factors such as connectivity and brand loyalty are affecting more in the medical division even though the story is different in other divisions. But affordability is one of the mostly considering factor in other tender processes.

Connectivity with tenderers and end users or else long relationship is also a main affecting factor and has positive relationship with the tender hit rate. When selecting best bidder tenderers consider about the others reference. So that bidders need to have strong relationship with the tenderers as well as end 
users. Sometimes customers may move to other products or tenderers can award the tender to the other bidders even though their prices are high. This is due to the strong relationship among those parties. Achieving the tenderers' requirement is also affecting highly to achieve the higher hit rate. Technical specification of the tender is another main considering factor, especially in the medical equipment field. World recognized brands can be easily matched with the tender specification. Tenderers are highly concern about this and if tender specifications are not matched with the bidding document, document reject at the first place. Achieving tenderer's requirement helps to award the tenders.

However, mistakes done by employees leads to gain lower tender hit rate. So that, there is negative relationship between tender hit rate and employee errors. Employees should have to pay their attention towards their work. Brand loyalty is another highly affecting factor to the tender hit rate. According to my view point brand loyalty is the highly affecting factor. As brand loyalty I brought few factors together to support for the discussion of the study. Under brand loyalty I discussed about quality of the product and brand of the product. This medical equipment industry deals with the human lives. So that tenderers are very careful about the quality and the brands. They always trust world recognized brands because they never take risk with human lives. Fast trouble shooting makes the favorable impact to the tender winnings. In the medical field, equipment should be free from errors and down time should be very less. After sales service should be perfect. The brand can be a reputed one, but if the after sales services are very slow and weak tenderers may not choose the product. Bribery is another factor which I have identified during the discussion of the study. Tender hit rate will have fallen down if other competitors give bribes to the tenders that means there is negative relationship between tender hit rate and bribery. This has become a major problem in Sri Lanka. Tendering field also same about the bribes. Sometimes transparency of the tendering process is questionable. This factor has become unavoidable and it creates negative impact to the tender hit rate.

Higher number of rivalries is another reason for achieving low tender hit rate for some of the products. Medical equipment field is operating in highly competitive environment. It is very difficult to guess the competitors bidding price when there are many competitors. Also winning chance is very low when number of employees are high. Good comments given by the previous users and if the products are available in many places may award higher number of tenders. In the medical equipment industry tenderers consider other users experience about the product. If they are buying product at first time, surely tenderers use others' references and availability. Quality certificates and registration also creates the impact to the tender hit rate medical equipment industry. Without quality certificates and essential registration tenderers does not accept the bidding document even. According to the Sri Lankan law every medical equipment should have to registered in the Ministry of health. Finally, I have identified some emerging factors as well. Country of origin and organizational factors are the 
emerging factors I have identified. I was unable to find literature support for these factors. Country of origin is factor that only consider in the medical equipment field. As organizational factors I have identified past experience of bidder and financial stability of the bidder.

\section{Conclusions}

This research is designed to explore the factors influencing the tender hit rate of Medical division of $\mathrm{ABC}$ holdings (Pvt) Ltd. Most of the literature found in relating to the tendering field are concerning about the tenders in construction industry. Therefore, I hope this study will contribute to the existing literature relating to the tenders as well this will contribute to the tenders that relate to the field of medical equipment. Aje, et al. (2016) [4]'s study emphasized the factors influencing the success rate of construction works in South-East-Nigeria. Not only that, Ayoti, B. (2012) [11] emphasized factors influencing effectiveness in tendering process in public sector. Accordingly, some of the existing literature focused on factors influencing the tender hit rate in different industries. But existing literature aimed at countries other than Sri Lanka. There was no any literature relevant to the Sri Lankan context. Therefore, I think this research will contribute to the literature relating to the factors influencing tender hit rate of medical equipment industry. Since this study is related to the $A B C$ holdings (Pvt) Ltd. which is Sri Lankan company. The research will contribute to the Sri Lankan literature relating to the tendering. Furthermore, this research contributes to existing knowledge regarding tendering since it provides an insight of the factors influencing the tender hit rate.

There are some limitations I have identified from this research such as, within the limited time scope it will be difficult to utilize the qualitative research approach because it's time consuming and has to pay individual attention to each and every participant. Main limitation I have found in this study is lack of literature available relating to tenders of medical field. Also, data gathered from the qualitative methods are less easy to generalize the bidders in every industry. It was difficult to make the systematic comparison because respondents gave widely differing responses. With the business of the employees who worked in $\mathrm{ABC}$ holdings, I had to limit some of the interviews to 10 minutes. I suggested for future researches to conduct researches regarding to how to develop the factors influencing tender hit rate such as how to develop the quality of the product. Further I suggest to conduct a research regarding to methods of improving the tender hit rate and reasons for lower tender hit rates. Moreover, this research can be done by increasing samples. That means research can be done by taking other bidders which relate to medical equipment field. That will be more effective than this research. Because in here I only take one bidder.

\section{Conflicts of Interest}

The author declares no conflicts of interest regarding the publication of this paper. 


\section{References}

[1] Muhamed, N. (n.d.) Tradex LLC. Printerest. https://www.pinterest.com/pin/722827808915533953/

[2] Department of Commerce, USA (2016) 2016 Top Markets Report Medical Devices. International Trade Administration.

[3] The Business Research Company (2020) Global Medical Device Market 2020 Size to Increase Due to Rising Infectious and Chronic Disease Cases as per the Business Research Company's Medical Devices Global Market Opportunities and Strategies-Global Forecast to 2030. GlobeNewswire. https://www.globenewswire.com/news-release/2020/10/27/2114984/0/en/Global-Me di-

cal-Device-Market-2020-Size-To-Increase-Due-To-Rising-Infectious-And-ChronicDis-

ease-Cases-As-Per-The-Business-Research-Company-s-Medical-Devices-Global-M arket-Opportuni.html\#:

[4] Aje, I., Oladinrin, T. and Nwaole, A. (2016) Factors Influencing Success Rate of Contractors in Competitive Bidding for Construction Works in South-East-Nigeria. Journal of Construction in Developing Countries, 21, 19-34.

https://doi.org/10.21315/jcdc2016.21.1.2

[5] Lauesen, S. and Vium, J. (n.d.) Communication Gaps in a Tender Process.

[6] Lauesen, S. and Vium, J. (n.d.) Experiences from a Tender Process.

[7] Alexandersson, G. and Hultén, S. (2006) Theory and Practice of Competitive Tenders in Passenger Railway Services.

[8] McGuire, J. (2006) Optimizing the Success Rate of Competitive Construction Bidding.

[9] Ngugi, J. and Mugo, H. (n.d.) Internal Factors Affecting Procurement Process of Supplies in the Public Sector; a Survey of Kenya Government Ministries.

[10] Thushara, R. (2018) Two Companies Favoured for Tender. Daily News e-Paper. https://epaper.dailynews.lk

[11] Ayoti, B. (2012) Factors Influencing Effectiveness in Tendering Process in Public Sector, the Case of Nyeri County, Kenya.

[12] Kissi, E., Adjei-Kumi, T., Badu, E. and Boateng, E. (2017) Factors Affecting Tender Price in the Ghanaian Construction Industry. Journal of Financial Management of Property and Construction, 22, 252-268. https://doi.org/10.1108/JFMPC-09-2016-0044

[13] Invest Northern Ireland (2012) Successful Tendering Guide; the Tender Process.

[14] Lemberg, J. (2013) Factors Influencing the Bid/No Bid Decision Making and the Success of Contract Bids in the Telecommunication Industry.

[15] Carbonara, N., Gunnigan, L., Pellegrino, R. and Sciancalepore, F. (2012) Tendering Procedures in PPP. School of Surveying and Construction Management. 